\title{
Research of the Industry Competitiveness in Xi'an Hi-Tech Zone
}

\author{
Xiuhan Lin \\ Beijing Beifang Private Middle School, Beijing, China \\ Email: LINXIUHAN1011@163.com
}

Received October 2015

\begin{abstract}
The research of the industry competitiveness in Xi'an Hi-tech Zone has an important role in promoting the industry competitiveness and shaping the industry characteristics. The paper first constructs the index system and algorithm model based on diamond model and then evaluates the industry competitiveness in Xi'an Hi-tech Zone using the data from the questionnaire. The evaluation result shows that the automotive industry, semiconductor, telecommunication, software and service industry are competitive among Xi'an Hi-tech Zone's industries, while electronic components industry, mechatronics and medical devices industry ranked last three. Based on this, the paper points that the strategic emerging industries like advanced manufacturing industry, telecommunication etc. are more competitive among Xi'an Hi-tech Zone's industries and have better development foreground.
\end{abstract}

\section{Keywords}

Diamond Model, Xi'an Hi-Tech Zone, Industry Competitiveness, Evaluation

\section{Introduction}

The Xi'an Hi-tech Industries Development Zone (the Xi'an Hi-tech Zone) is the first national-level hi-tech industrial zone approved by the State Council in March 1993, which makes great contribution to the development of high-tech industry and the optimization and upgrade of industrial structure. In 2014, the Xi' an Hi-tech Zone's general income grossed over a trillion Yuan for the first time (1.1070 trillion Yuan), ranking the third among all the High-tech Zones in China. Its leading economic indicator keeps growing by $30 \%$ for a decade. In Xi'an Hi-tech Zone, there are one enterprise whose operating income achieved over 100 billion, 17 companies with the operating income of 10 billion, 26 enterprises with the turnover of 5 billion and 83 enterprises' operating income exceeds a billion. Although the Xi'an Hi-tech Zone developing for over 20 years has already explored a successful way, there is still a lot of room for it to improve industrial competition or create industrial characteristic compared with other hi-tech zones. So it is a valuable research topic to test and analyze Xi'an Hi-tech Zone's industry competitiveness and propose thoughts of industrial development based on the competitiveness analysis.

In the research of industry competitiveness, "diamond model" attracts many scholars attention. "Diamond model" proposed by Michael. Porter in "The Competitive Advantage of Nations" (1990) indicates that national industry competitiveness is mainly influenced by the integrate function of four basic elements and two auxiliary 
elements. These elements are interactional and constitute an interrelated and interacted system, called "diamond model”. The four basic elements include: 1) Factors of Production: These factors include human resource, natural resource, knowledge resource, and capital resource and infrastructure construction; 2) Demand conditions: mainly refer to domestic market demand; 3) Performance of related and supportive industry: whether these industry and upstream have international competition; 4) Enterprises' strategies, structures and performance of their competitors.

Government and opportunity, as auxiliary elements, also play important roles in influencing industry competitive edge. After the model was proposed, many scholars apply this model to competitive analysis of different countries and different industries. Wayne, Rugman and D'ruz used the diamond model to analyze the advantages of the industry competitiveness of New Zealand and Canada respectively [1] [2]. Liu Yingqi et al. (2006) built an index system for dominant industry selection model in poor areas of western China and use Wengniutekulun county of Inner Mongolia autonomous region as an example to analyze different industries' ranks by using the "diamond model" [3]. Zhao Bing, Liu Min and Shu Zhen applied the model to regional competitiveness research and they studied the competitiveness of pharmaceutical industry in Shi Jiazhuang City and Jiangsu province [4] [5]. Shi Zhuohong and Zhu Hailing, Fang Hui and Shang Yanan researched industry competitiveness of strategic emerging industry and cultural trade in China using this model [6] [7].

Based on this, this paper is built on the "diamond model" and constructs the Xi'an Hi-tech Zone industry competitiveness index System, using Experts Grading Method to determine weight at different levels. Then the paper evaluates the competitiveness of the Xi'an Hi-tech Zone and put forward suggestions accordingly.

\section{Evaluation Model of Industry Competitiveness in Xi'an Hi-Tech Zone}

\subsection{Building the Industry Competitiveness Index System in Xi'an Hi-Tech Zone}

Differing from other economic regions, high-tech zones have special functions. As an intelligence-intensive and knowledge-intensive economic zone and a platform of developing knowledge economy, high-tech zones' industrial focus and competitiveness cannot reflect simply by adopting common indicator. Instead, new economic concept and measure method should be used to reflect high-tech zones' industrial focus and competitiveness. So this paper follows four rules when constructs hi-tech zone industry competitiveness index system: 1) In this system, there are indexes which can reflect industrial competitive advantages deeply and systematically; 2) The system should be objective and realistic and no overlapping index should exist in this system; 3) The evaluation index system should not only reflect industries' real development achievements but the process and potential of development; 4) A series of index reflecting development situation completely and correctly should be focused and the index should reflect the future trend and potential of industry development properly.

In compliance with design thoughts and estimating principle, this paper constructs the Xi'an Hi-tech Zone industry competitiveness index system on the in line with selecting and designing indexes which are stable, concise, acquirable and operable. This system includes 6 first class indicators and 18 second class indicators (Table 1).

Table 1. The industry competitiveness index system in the Xi'an Hi-tech Zone.

\begin{tabular}{|c|c|c|c|}
\hline First class indicator & Second class indicator & First class indicator & Second class indicator \\
\hline \multirow{4}{*}{$\begin{array}{l}\text { Production } \\
\text { element }\end{array}$} & Human resource condition & Demand condition & Market demand \\
\hline & Technology resource condition & \multirow{3}{*}{$\begin{array}{l}\text { Enterprise strategy, } \\
\text { structure and competition }\end{array}$} & Competition among enterprises \\
\hline & Traffic condition & & Inter-enterprise cooperation \\
\hline & Agency & & Degree of industrial cluster \\
\hline \multirow{6}{*}{$\begin{array}{l}\text { Related and } \\
\text { supportive } \\
\text { industry }\end{array}$} & Difficulty of loan & \multirow{3}{*}{ Government } & Substitutes \\
\hline & Source of key equipment & & Government support \\
\hline & Position in the industry value chain & & Improve investment environment \\
\hline & Upstream industry competitive advantage & \multirow{3}{*}{ Opportunity } & \multirow{3}{*}{ The opportunity to develop } \\
\hline & Downstream industry competitive advantage & & \\
\hline & Extension situation of network sales & & \\
\hline
\end{tabular}




\subsection{Algorithmic Mode}

Suppose there are $n$ industries and $m$ elements, with the $i$-th element having $l_{i}$ indicators. Assume the value of the $j$-th indicator of the $i$-th element in the $n$-th industry is

$$
x_{k, i, j}, k=1, \cdots, n, i=1, \cdots, m, j=1, \cdots, l_{i}
$$

The weight of indicator is

$$
y_{k, i, j}, k=1, \cdots, n, i=1, \cdots, m, j=1, \cdots, l_{i}
$$

Firstly, the linear transformation method is used to turn each indicator value in a standard score as 0 - 100 let

$$
z_{k, i, j}=\frac{x_{k, i, j}}{\max \left(x_{k, i, j}, k=1, \cdots, n\right)} * 100
$$

$z_{k, i, j}$ is the standard score of the $j$-th indicator of the $i$-th element in the $n$-th industry.

$$
\alpha_{k, i}=\sum_{j=1}^{l_{i}} \omega_{i, j} * y_{k, i, j}, j=1, \cdots, l_{i}
$$

After standardizing the standard score, calculated the indicators of each element:

$\alpha_{k, i}$ is the standard results of $i$-th element in the $n$-th industry.

\section{Competitiveness Evaluation of Xi'an Hi-Tech Zone's Industries}

\subsection{Competitiveness Evaluation of Xi'an Hi-Tech Zone's Industries}

When selecting the industries in Xi'an Hi-tech Zone, four dominant industries are selected firstly: electronic information, advanced manufacture, pharmaceutical industry and modern service industry. Then these four industries are subdivided into 12 subsidiary industries. The industrial connotation of modern service industry is opulent. This paper analyzes the cultural creativity industry contained by modern service industry by combining the industrial development situation and the questionnaire survey data. Besides, considering the national condition

\begin{tabular}{|c|c|}
\hline Name of dominant industry & Sub-industry \\
\hline \multirow{4}{*}{ Telecommunication industry } & Software and service outsourcing \\
\hline & Electronic components industry \\
\hline & Semiconductor industry \\
\hline & Telecommunication industry \\
\hline \multirow{4}{*}{$\begin{array}{l}\text { Advanced manufacturing } \\
\text { industry }\end{array}$} & Electronic equipment industry \\
\hline & Mechatronics industry \\
\hline & Automobile industry \\
\hline & General and professional equipment industry \\
\hline \multirow{3}{*}{ Bio-medicine industry } & Energy equipment industry \\
\hline & Pharmaceutical industry \\
\hline & Medical devices industry \\
\hline \multirow[t]{2}{*}{ Modern service industry } & Culture creativity industry \\
\hline & Environment protection and energy saving \\
\hline \multirow{3}{*}{ Others } & Material (new material) \\
\hline & New energy (photovoltaic) \\
\hline & Service industry \\
\hline
\end{tabular}
of China and frontier technology, this paper also selects four industries to evaluate, including environment protection and energy saving, advanced material, new energy and service industry (Table 2).

Table 2. Dominant industries classification in Xi'an Hi-tech Zone. 


\subsection{Evaluation Results of Different Industries with Various Elements}

This paper designs the questionnaire using the measure indicator system. 25 questions are included in this questionnaire and related personnel in Xi'an Hi-tech Zone are selected to be the inquisition object. 1503 questionnaires have been collected and 1385 questionnaires are valid, with 92.15\% efficiency. This paper utilizes algorithm model to deal with the data, and the results are shown in the Table 3.

\subsection{Results for Industry Competitiveness}

This paper determines weight for competitiveness further by use experts grading method and calculates Xi'an Hi-tech Zone's industrial competition.

Table 4 gives the information that the automotive industry, semiconductor, telecommunication, software and service industry are competitive among Xi' an Hi-tech Zone's industries, while electronic components industry, mechatronics and medical devices industry range the last three.

\section{Conclusions}

This paper is based on the "diamond model" and constructs the Xi'an Hi-tech Zone industry competitiveness index System, using Experts Grading Method to determine weight at different levels. Then calculate and sequence the competitiveness of the Xi'an Hi-tech Zone. This paper addresses three conclusions that arose from the evaluation:

1) The advanced manufacturing industry is more competitive and general and special equipment industry is an industry who has high relevance with others. General and professional equipment of advanced manufacturing industry have a solid foundation, many enterprises such as Brother Machinery Co. Ltd., Beicun Precision Machinery Co. Ltd., the Northwest Machine Factory, Edward Measurement Ltd. provide supports for many industries. Telecommunication industry is associated with many other industries in the Xi'an Hi-tech Zone, including telecommunication, semiconductor, software, automotive, pharmaceutical industry and so on. The advanced manufacturing industry plays a significant role in the Xi'an Hi-tech Zones' industrial competition and development, providing the foundation for the development of advanced equipment manufacturing industry.

Table 3. Evaluation results of different industries with various elements in Xi'an Hi-tech Zone.

\begin{tabular}{|c|c|c|c|c|c|c|}
\hline Industry & $\begin{array}{c}\text { Production } \\
\text { elements }\end{array}$ & $\begin{array}{l}\text { Market } \\
\text { demand }\end{array}$ & $\begin{array}{c}\text { Related } \\
\text { and support } \\
\text { industry }\end{array}$ & $\begin{array}{c}\text { Trade } \\
\text { competition }\end{array}$ & Government & $\begin{array}{c}\text { Industry } \\
\text { development } \\
\text { opportunity }\end{array}$ \\
\hline Software and service outsourcing & 64.29 & 66.86 & 57.78 & 55.61 & 66.93 & 73 \\
\hline Electronic components industry & 64.62 & 61.71 & 55.8 & 52.25 & 61.5 & 68.86 \\
\hline Electronic equipment industry & 65.33 & 63.29 & 57.57 & 54.04 & 62.14 & 69.57 \\
\hline Semiconductor industry & 66.19 & 68.29 & 53.37 & 49.5 & 74.14 & 78.57 \\
\hline Environment protection and energy saving & 63.52 & 62.43 & 55.88 & 49.32 & 63.71 & 73.29 \\
\hline Energy equipment industry & 61.67 & 66.43 & 56.35 & 47.96 & 64.36 & 72.43 \\
\hline Automobile industry & 70.1 & 69.71 & 58.9 & 47.61 & 72.36 & 77.71 \\
\hline Pharmaceutical industry & 65.14 & 65.14 & 57.47 & 53.07 & 64.79 & 71.86 \\
\hline Culturecreativity industry & 64.33 & 65.57 & 59.29 & 57.89 & 65 & 71.57 \\
\hline Generalandprofessional equipment industry & 66.57 & 67.86 & 55.96 & 49.75 & 64.29 & 73.43 \\
\hline New material & 67 & 74 & 57.27 & 50.75 & 66.64 & 73.71 \\
\hline Service industry & 62.76 & 62 & 56.9 & 56.29 & 62.93 & 68.43 \\
\hline Telecommunication industry & 65.38 & 66.57 & 57.92 & 57.57 & 67.07 & 71.29 \\
\hline Mechatronics industry & 62.38 & 56.14 & 53.51 & 52.79 & 56.57 & 69.14 \\
\hline Medical devices industry & 64.81 & 64.29 & 50.94 & 42.82 & 49.43 & 65.14 \\
\hline
\end{tabular}


Table 4. Results and ranks for industry competitiveness in Xi’an Hi-tech Zone.

\begin{tabular}{ccc}
\hline Name of industry & Score & Rank \\
\hline Automobile industry & 69.32 & 1 \\
Semiconductor industry & 68.5 & 2 \\
New material industry & 67.08 & 4 \\
Telecommunication industry & 66.63 & 5 \\
Software and service outsourcing & 66.06 & 6 \\
Culture creativity & 63.45 & 7 \\
New energy (photovoltaic) & 60.18 & 8 \\
pharmaceutical industry & 57.87 & 9 \\
Seneral and professional equipment industry & 56.5 & 10 \\
Electronic equipment industry & 51.94 & 11 \\
Energy equipment industry & 51.84 & 12 \\
Environment protection and energy saving & 49.73 & 13 \\
Electronic components industry & 47.89 & 14 \\
Mechatronics industry & 45.17 & 33.56 \\
\hline
\end{tabular}

2) Industry segmentation of the telecommunication has stronger competitive power than others. Telecommunication, software, service outsourcing and semiconductor industry rank at the top among all the industries. The file State Council's decision on accelerating the cultivation and development of strategic emerging industries lists 7 national strategic emerging industries system, including new telecommunication industry, existing integrate circuit industry of the semiconductor, software and service outsourcing, internet service, creative industries. All of these are the content of a new generation information technology and have already set up foundation of industrial development and competitiveness, and have space and ability to develop.

3) Based on the situation of china and industrial base, China selects 7 industries to develop the strategic emerging industries at this stage, such as environmental protection, a new generation of information technology, biotechnology, advanced equipment manufacturing, new energy, new material and alternative fuel vehicles. These industries all have industrial base and are associated with other industries in the Xi' an Hi-tech Zone. Most of the enterprises introduced from the world top 500 enterprise in the Xi'an Hi-tech Zone are strategic emerging industries. These industries match with the layout of national strategic emerging industries, for example, the distribution of the research center promotes the development of researching service industries in the Xi'an Hi-tech Zone. And the introduction of new energy, new material and the top 500 companies in environment protection industries is beneficial to maintain a sustainable competitive advantage and enhance the industries' competition and provide supports for the development of strategic emerging industries in Xi'an province.

\section{References}

[1] Cartwright, W.R. (1993) Multiple Linked Diamonds and the International Competitiveness of Export-Dependent Industries: The New Zealand Experience. J. Management International Review, Second Quarter.

[2] Rugman, et al. (1993) The Double Diamond Model of International Competitiveness: The Canadian Experience. Management International Review, Second Quarter.

[3] Liu, Y.Q., Li, X.W. and Li, X.M. (2006) Studies on Selection Model of Dominant Industries Based on Diamond Theory. China Soft Science Magazine. (In Chinese)

[4] Zhao, B., Zhang, D.S. and Zhao, Y.Z. (2011) The Study on Regional Medical Industry Competitiveness Based on Di- 
amond Model—Taking Shi Jiazhuang as an Example. J. China Biotechnology, 31, 140-145. (In Chinese)

[5] Liu, M. and Chu, S.Z. (2011) Research on Medical Industry Competitiveness in Jiang Su Province Based on Diamond Model. Shanghai Journal of Medicine and Medicine, 32, 27-31. (In Chinese)

[6] Shi, Z.H. and Zhu, H.L. (2014) Establishing Evaluation System of Strategic Emerging Industries Based on Diamond Model. J. Statistics and Decision, 10, 51-53. (In Chinese)

[7] Fang, H. and Shang, Y. (2012) Research on Chinese Cultural Trade Competition Based on Dynamical Diamond Model. J. World Economy Study, 1, 44-50+88. (In Chinese) 